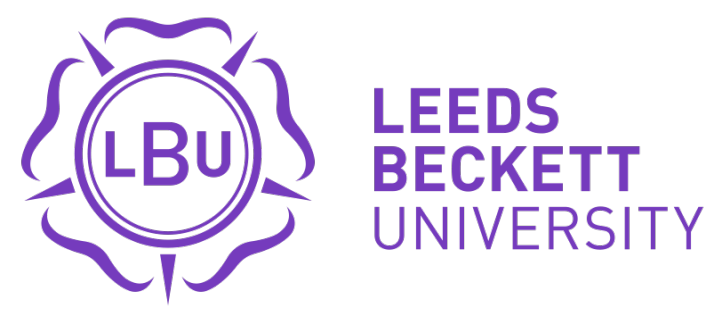

Citation:

Hendricks, MS and Den Hollender, S and Tam, N and Brown, JC and Lambert, M (2015) The relationships between rugby players' tackle training attitudes and behaviour and their match tackle attitudes and behaviour. BMJ Open Sport and Exercise Medicine, 1 (1). ISSN 2055-7647 DOI: https://doi.org/10.1136/bmjsem-2015-000046

Link to Leeds Beckett Repository record:

https://eprints.leedsbeckett.ac.uk/id/eprint/2909/

Document Version:

Article (Published Version)

Creative Commons: Attribution-Noncommercial 3.0

The aim of the Leeds Beckett Repository is to provide open access to our research, as required by funder policies and permitted by publishers and copyright law.

The Leeds Beckett repository holds a wide range of publications, each of which has been checked for copyright and the relevant embargo period has been applied by the Research Services team.

We operate on a standard take-down policy. If you are the author or publisher of an output and you would like it removed from the repository, please contact us and we will investigate on a case-by-case basis.

Each thesis in the repository has been cleared where necessary by the author for third party copyright. If you would like a thesis to be removed from the repository or believe there is an issue with copyright, please contact us on openaccess@leedsbeckett.ac.uk and we will investigate on a case-by-case basis. 
BMJ Open

Sport \&

Exercise

Medicine

\title{
The relationships between rugby players' tackle training attitudes and behaviour and their match tackle attitudes and behaviour
}

\author{
Sharief Hendricks, Steve den Hollander, Nicholas Tam, James Brown, \\ Michael Lambert
}

To cite: Hendricks S, den Hollander S, Tam N, et al. The relationships between rugby players' tackle training attitudes and behaviour and their match tackle attitudes and behaviour. BMJ Open Sport Exerc Med 2015;0: e000046. doi:10.1136/ bmjsem-2015-000046

- Prepublication history for this paper is available online. To view these files please visit the journal online (http://dx.doi.org/10.1136/ bmjsem-2015-000046).

Accepted 6 September 2015

CrossMark

Division of Exercise Science and Sports Medicine, Department of Human Biology, Faculty of Health Sciences, University of Cape Town, Cape Town,

South Africa

Correspondence to Dr Sharief Hendricks; sharief.hendricks01@gmail. com

\section{ABSTRACT}

Background: The tackle event in rugby is a technical and physical contest between opposing players. A player's ability to tolerate and contest during a tackle is a prerequisite for safe participation and success in rugby. Little is known about the relationship between tackle training and tackling in matches in rugby union. Therefore, we investigated the relationships between players' training attitudes and behaviour and their match attitudes and behaviour for tackling in rugby union.

Method: A questionnaire was designed to assess attitude (importance) and behaviours (frequency and quantity) among junior (under 19) players on a 5-point Likert Scale. Questionnaires were handed out to 220 players (10 schools) at a tournament and $75 \%$ (9 schools, $n=164$ ) were returned for analysis. Associations between training attitudes and behaviours were tested using the $\chi^{2}$ test, Cramer's V and $\tau$-b. Results: The more time spent on emphasising proper technique to prevent injuries in training, the more important players rated 'own safety' $(\tau-b=0.21$, moderate, $z=3.1, p<0.01)$, 'going for the ball only' $(\tau-b=0.27$, moderate, $z=4.6, p<0.001)$ and 'staying on feet' $(\tau-b=0.23$, moderate, $z=3.6, p<0.001)$ in match play. The more time spent on emphasising proper technique to improve performance in training, the more important players rated actions 'going for ball only' $(\tau-b=0.23$, moderate, $z=3.7, p<0.001)$ and 'preventing the ball carrier from retaining position' $(\tau-b=0.20$, moderate, $z=3.1, p<0.01)$ in match play.

Conclusions: This is the first study to report on the relationships between players' training attitudes and behaviour and their match attitudes and behaviours for tackling in rugby union. The importance of tackle training to prevent injury, and the amount of time spent on technique to prevent injuries, was associated with behaviours that reduce the risk of injury in matches.

\section{INTRODUCTION}

Attitude refers to "the knowledge and beliefs of a person concerning the specific consequences of a certain form of behaviour'. 12
Behaviour can either be considered planned with the intention to perform specific actions, or it can be considered unconscious and automated. ${ }^{3}$ Behaviour is typically influenced by self-efficacy (ability to perform the intended skill), social influences (social norms), and attitude and intention-known as behavioural determinants. ${ }^{1-7}$ The relationship between behaviour and attitude is not unilateral as behaviour may modify the attitude of an individual. ${ }^{4-6}$

The attitude and behaviour of players/ athletes towards safety have been identified as risk factors for injury in sport. ${ }^{1}{ }^{8-13}$ Understanding the attitudes and behaviours of players are particularly important for designing and implementing injury prevention programmes. ${ }^{14-17}$ Studies on the attitudes and behaviours of players towards safety in sport are lacking. ${ }^{10} 16$ This paucity of research is even truer in rugby, with only one study on the players' attitudes and behaviours specifically for the contact area of play. ${ }^{16}$

The relationship between training and competition in sport is well established. ${ }^{18} 19$ In particular, it is known that competition-specific training is associated with superior performance in competition, compared with nonspecific training. ${ }^{18}$ In rugby union, training volume, movements in training and physical fitness of players in training have been related to match injury, match movement demands and match activities, respectively. ${ }^{20-22}$ Less is understood about the relationship between rugby skills in training and rugby skill behaviours in matches.

The tackle event in rugby union is a technical and physical contest between the player in possession of the ball (known as ball carrier) and the opposing player attempting to regain possession of the ball (known as the tackler). ${ }^{23}$ Players engage in 10-25 
tackles (whether as a ball carrier or tackler) during a match depending on their positional role in the team. ${ }^{24} 25$ The nature of two or more bodies physically engaging at such frequencies and sometimes at high speeds exposes players to muscle damage and a high risk of injury. ${ }^{26}{ }^{27}$ Tackle-related injuries account for up to $61 \%$ of all injuries during a rugby match. ${ }^{23} 2728$ Thus, players' ability to tolerate and contest tackle events (whether as a ball carrier or tackler) is a prerequisite for safe participation and success in rugby. ${ }^{29}$ Not much is known about training for the tackle and how this translates into performance of the tackle in matches. Therefore, we aimed to investigate the relationships between players' training attitudes and behaviour and their match attitudes and behaviour for tackling in rugby union.

\section{METHODS}

The data collection of the broader study, of which this study forms a part, is described in more detail elsewhere. ${ }^{16}$

\section{Participants}

The questionnaire was administered at the Cape School's Week Rugby Festival. The Cape School's Week Rugby Festival comprises of 10 traditionally rugby playing schools from the Western, Northern and Eastern Cape regions in South Africa. Only the under 19 A (1st team) sides of each school participated in the rugby festival. Twenty-two questionnaires were administered to 10 schools, and 164 questionnaires (9 out of the 10 schools participated) were returned, representing a $75 \%$ response rate. Three teams completed the questionnaire in examination-like conditions with the principle investigator present, two teams completed the questionnaire after a team meeting in a room with the principle investigator present and the remaining four teams' coaches or managers were handed the questionnaires, which they completed on their own and returned at a later stage. Where the researchers were not present, coaches and managers were asked to monitor the players filling out the questionnaire. In the cases where the researchers were present, players completed the questionnaire in approximately 10-15 min. Informed consent was obtained from the coaches or managers of each team, and informed assent was obtained from each player. Ethical approval for this study was granted by the University of Cape Town Human Research Ethics Committee.

\section{Questionnaire developmental process}

The developmental process of the questionnaire began with a list of possible general and specific tackle training open-ended questions. Some questions were guided by previous research on the tackle. ${ }^{23} 3031$ The list of questions was then presented to a panel of coaches, sport scientists and rugby administrators to further discuss the efficacy, reasoning and validity of the questions. This process of refinement was conducted 2-3 times before a list of questions was finalised. The next step in the developmental process was to design the questionnaire itself with regard to structure, order, flow and answerability. To effectively achieve the best design for the questionnaire, guidelines for designing surveys and social science research methods were used. ${ }^{32-34}$

\section{Question and item format and scale definitions}

It was decided that closed-ended questions would be more appropriate for purposes of this study as these provide the respondents with a prespecified set of answers (items) and response categories. ${ }^{33}$ This suited the aim of the study as it made answering the questionnaire less demanding for the players, and standardised the data for statistical analysis, making it more reliable and consistent over time. ${ }^{33}$ Accordingly, each question consisted of (1) the question (2) the items-list of possible answers relating to the specific question being posed (3) response categories-a five-point ordinal Likert scale represented by a numerical value, where players had to rate the importance, frequency and quantity of each item in the question. Where necessary, questions were provided with a 'Not Familiar' option to prevent players from giving arbitrary answers if they were unsure. ${ }^{33}$ For assessing players' attitude, players had to rate the importance of an item on the following scale: (1) not at all important, (2) not too important, (3) undecided, (4) somewhat important, (5) very important. $^{33}$ To measure frequency of training and match behaviour, the following descriptors were used: (1) never, (2) rarely, (3) sometimes, (4) frequently, (5) always. ${ }^{28}$ Quantity of training or match behaviour was determined on the scale: (1) not at all, (2) a little, (3) a fair amount, (4) much, (5) very much. ${ }^{33}$ Although all questions were closed questions, a 'further comment' space was provided to cater for players who felt the need to add more information.

\section{Questions domains and layout}

The final questionnaire consisted of 12 questions on training with a total of 109 items and 4 match questions with a total of 52 items (see Hendricks $e t a l^{16}$ for complete questionnaire). For the purpose of this study, the association between two attitudinal and three behavioural training questions were tested against one attitudinal and one behavioural match question. The first attitudinal training question asked players to rate the importance of training proper technique for injury prevention and performance, and the second attitudinal training question asked players to rate the importance of training tackling for injury prevention and performance. Injury prevention was defined as 'lowering the risk of getting injured during the tackle', and improved tackle performance was defined as 'preventing the ball carrier from gaining territory and the ball carriers' team from retaining the ball'. The three behavioural training questions examined how much emphasis is placed on injury prevention and 
performance in training, how much influence different coaching methods have on tackle technique and how frequently players trained the different types of tackles. The match attitudinal question asked players 'What is important to you when making a tackle during a match?' and listed 11 items. Although not explicitly stated, of the 11 items, 3 were related to injury prevention only (own safety, safety of ball-carrier and safety of you and ball carrier), 5 were related to performance only (bring down ball carrier at all cost, putting in a big hit, preventing the ball carrier from retaining possession and preventing the ball carrier team from retaining possession), and 3 were related to injury prevention and performance (doing what is practised, proper technique and staying on your feet). The one match behaviour question examined how often players executed the different types of tackles during a match.

The wording of all questions and items were as clear and unambiguous as possible and definitions, commensurate with the age of the respondents, were provided. Questions were divided into training questions and match questions. This was indicated as section A (training) and section B (match) in the questionnaire.

Each question was placed in a separate box, and each question box was colour coded for players to differentiate between question, item and response category on the scale. Depending on the number of items on the list, no more than three questions were allowed per page. In addition, the cover page was attached to the questionnaire and provided space for players' personal information and playing history. This included school, playing position, highest level played and playing experience. The revised questionnaire was once again presented to the panel of coaches, sport scientists and rugby administrators for final comments. The questionnaire was pretested with 24 University of Cape Town Varsity Cup players to expose any unclear or incomprehensible questions. Minor typographical errors were identified during this process and corrected.

\section{Data analysis}

The relationship between each item for each training question (except the question on the frequency of training the different types of tackles) was independently tested against each of the 11 items listed for the attitudinal match question. The behavioural training question on how frequently players trained the different types of tackles was associated with the behavioural match question on how much the different types of tackles are executed during matches. To test whether items in training were associated with items in the match, the $\chi^{2}$ test was used with a priori $\alpha$ level of significance set at $p<0.05$. The magnitude of the association was tested using Cramer's V, with values between 0 and 0.19 considered weak, 0.20 and 0.49 considered moderate, and more than 0.50 considered strong. Because the Likert data were ordinal, the order of association was also tested using $\tau$-b. A $\tau$-b value of less than 0.2 signifies a weak relationship, between 0.2 and 0.49 indicates a moderate relationship, and 0.5 and higher signifies a strong relationship. The $\mathrm{z}$ test value was also determined to test the significance of the relationship; $|z| \geq 1.96$ is significant at the $p<0.05$ level, $|z| \geq 2.60$ is significant at the $p<0.01$ level and $|z| \geq 3.32$ is significant at the $p<0.001$ level. Data were reported as percentage frequencies $(\%)$.

\section{RESULTS}

The importance of proper technique for injury prevention in training was associated with 'doing what is practised' $\left(\chi^{2}(16)=24.33, \mathrm{p}=0.08\right)$, 'own safety' $\left(\chi^{2}(16)\right.$ $=24.75, \mathrm{p}=0.07)$, 'putting in a big hit' $\left(\chi^{2}(16)=29.65\right.$, $\mathrm{p}=0.02$ ) and 'preventing the ball carrier from retaining possession' $\left(\chi^{2}(12)=20.89, \mathrm{p}=0.05\right)$ in match play. The relationship between the importance of proper technique for injury prevention was moderate for 'putting in a big hit' (Cramer's V=0.22) and 'preventing the ball carrier from retaining possession (Cramer's $\mathrm{V}=0.21$ ) in match play. The more important players rated proper technique for injury prevention in training; the more important 'preventing the ball carrier from retaining possession' was rated ( $40 \%$ rated very important, $\tau-\mathrm{b}=0.26$, moderate, $\mathrm{z}=3.7, \mathrm{p}<0.001$ ) in match play.

The importance of proper technique for improving performance in training was associated with 'preventing the ball carrier from retaining possession' $\left(\chi^{2}(9)=27.59\right.$, $\mathrm{p}=0.001)$ and 'preventing the ball carrier team from retaining possession' $\left(\chi^{2}(12)=21.55, \mathrm{p}=0.04\right)$ in match play. The relationship between the importance of proper technique for improving performance in training was moderate for 'preventing the ball carrier from retaining possession' (Cramer's V=0.24) and 'preventing the ball carrier team from retaining possession' (Cramer's V=0.24) in match play. The more important players rated the importance of proper technique for improving performance in training; the more important players rated 'preventing the ball carrier team from retaining possession' ( $46 \%$ rated very important, $\tau-\mathrm{b}=0.24$, moderate, $\mathrm{z}=3.2, \mathrm{p}<0.01)$ in match play.

The importance of training tackling for injury prevention was significantly associated with match play attitudes 'doing what is practised' $\left(\chi^{2} \quad(16)=26.50, p=0.047\right.$, Cramer's V=0.21, moderate), 'proper technique' $\left(\chi^{2}(16)=29.97, \mathrm{p}=0.018\right.$, Cramer's $\mathrm{V}=0.22$, moderate $)$ and 'own safety' $\left(\chi^{2} \quad(16)=37.16, \quad \mathrm{p}=0.002\right.$, Cramer's $\mathrm{V}=0.24$, moderate). The importance of training tackling was positively associated with 'own safety' (21\% rated very important, $10 \%$ somewhat important, $\tau$ - $\mathrm{b}=0.22$, moderate, $\mathrm{z}=3.4, \mathrm{p}<0.001$ ) in match play.

The importance of training tackling for improving performance was associated with match play attitudes 'putting in a big hit' $\left(\chi^{2}(16)=25.16, p=0.067\right.$, Cramer's $\mathrm{V}=0.20$, moderate), 'staying on your feet' $\left(\chi^{2}(16)=34.33\right.$, $\mathrm{p}=0.005$, Cramer's $\mathrm{V}=0.24$, moderate) and 'preventing the ball carrier from retaining possession' $\left(\chi^{2}(12)\right.$ $=27.49, \mathrm{p}=0.007$, Cramer's V=0.24, moderate). The 
importance of training tackling was positively associated with 'staying on your feet' (31\% rated very important, $10 \%$ somewhat important, $\tau-\mathrm{b}=0.24$, moderate, $\mathrm{z}=3.4$, $\mathrm{p}<0.001)$ and 'preventing the ball carrier from retaining possession' (42\% rated very important, $\tau$ - $\mathrm{b}=0.20$, moderate, $\mathrm{z}=2.6, \mathrm{p}<0.01)$ in match play.

The time spent on emphasising proper technique to prevent injuries in training was significantly associated with 'doing what is practised' $\left(\chi^{2}(16)=30.28, \mathrm{p}=0.017\right.$, Cramer's $\mathrm{V}=0.22$, moderate), 'proper technique' $\left(\chi^{2} \quad(16)=31.63\right.$, $\mathrm{p}=0.011$, Cramer's V $=0.22$, moderate), 'safety of ball carrier' $\left(\chi^{2}(16)=27.78, p=0.03\right.$, Cramer's $V=0.21$, moderate $)$, 'safety of both you and ball carrier' $\left(\chi^{2}(16)=27.02, \mathrm{p}=0.04\right.$, Cramer's V $=0.21$, moderate) and 'going for the ball only' $\left(\chi^{2}(16)=34.47, \mathrm{p}=0.005\right.$, Cramer's $\mathrm{V}=0.23$, moderate $)$ in match play. The more time spent on emphasising proper technique to prevent injuries in training, the more important players rated 'own safety' $(\tau-\mathrm{b}=0.21$, moderate, $\mathrm{z}=3.1$, $\mathrm{p}<0.01)$, 'going for the ball only' $(\tau-\mathrm{b}=0.27$, moderate, $\mathrm{z}=4.6, \mathrm{p}<0.001)$ and 'staying on feet' $(\tau-\mathrm{b}=0.23$, moderate, $\mathrm{z}=3.6, \mathrm{p}<0.001)$ in match play.

The time spent on emphasising proper technique to improve performance in training was significantly associated with executing 'proper technique' $\left(\chi^{2}(16)=33.67\right.$, $\mathrm{p}=0.006$, Cramer's $\mathrm{V}=0.23$, moderate) and 'staying on feet' $\left(\chi^{2}(16)=30.31, p=0.017\right.$, Cramer's $V=0.22$, moderate) in match play. The more time spent on emphasising proper technique to improve performance in training, the more important players rated actions 'going for ball only' ( $\tau-\mathrm{b}=0.23$, moderate, $\mathrm{z}=3.7, \mathrm{p}<0.001)$ and 'preventing the ball carrier from retaining position' $(\tau-\mathrm{b}=0.20$, moderate, $\mathrm{z}=3.1, \mathrm{p}<0.01$ ) in match play.

The association between coaching methods and match attitudes and behaviours are shown in tables 1 and 2 . The training frequency for the different type of tackles was associated with the number of times the different type of tackles was executed in matches (table 3). Front on tackles were executed most frequently in training (44\% much-very much) and most often in matches $(69 \%$ much-very much).

\section{DISCUSSION}

The importance of training proper technique to prepare for match play

This is the first study to report on the relationships between players' training and match attitudes and behaviours for tackling in rugby union. When asked about the general importance of proper technique to prevent injuries and improve performance, players associated the importance of proper technique in training to one of rugby's main objectives, which is to deny the opposition possession of the ball.

\section{Tackle training attitudes and behaviours transfer into} match play

The importance of tackle training to prevent injury, and the amount of time spent on technique to prevent injuries was positively associated with behaviours that reduce the risk of injury in matches. Likewise, the more important players considered tackle training for performance, and the more time spent on tackle technique training for performance, the more frequently players reported on behaviours that related to performance in matches.

Our findings demonstrate that the tackle knowledge and beliefs acquired in training transfer, to some extent, into match play-highlighting the training environment and coach as key agents for implementing injury prevention and performance programmes. Moreover, these findings offer support for the strategies of injury prevention and performance programmes in rugby union that conscribe to the model of educating coaches and informing training to effect match behaviour. Examples of such programmes are BokSmart ${ }^{35} 36$ and RugbySmart. ${ }^{11}$

\section{Verbal instruction and coach demonstration are effective coaching methods for training contact skills}

In separate analyses, verbal instruction by the coach (whether to the individual or to the team) and coach demonstration (whether to the individual or to the team) during training were moderately associated with five or more match behaviours. Match behaviours 'doing what is practised', 'proper technique', 'own safety' and 'staying on feet' were consistently associated with both verbal instruction and demonstration, irrespective of whether executed to an individual player or to the team.

The effectiveness of verbal instruction, demonstration or the combination of the two to train skill have been questioned compared with less prescriptive coaching methods. ${ }^{19}$ In the present study, the relationship between verbal instruction and demonstration, and match behaviours suggest that these coaching methods may be effective for training contact skills such as tackling. Engaging in tackle contact is a physically demanding and highly technical skill, and if not executed correctly, could lead to serious injury. ${ }^{23} 252637$ Therefore, offering a player a visual template or criterion model with instruction before engaging in match play contact will allow for safe and successful participation in rugby. Note, we have recommended previously that only once the player has acquired an advanced level of tackle contact skill, should less prescriptive methods be introduced. ${ }^{23}$

\section{The social context of the team should be considered when delivering technical instruction or demonstration}

Interestingly, 'identifying a problem in your own tackle technique and fixing it' was only associated with one match behaviour, 'going for the ball', whereas 'identifying a team problem in tackle technique and fixing it' was associated with 'doing what is practised', 'proper technique', 'own safety', 'going for the ball' and 'staying on feet'. The difference in match behaviour association between fixing a single player's tackle technique problem and fixing a team's tackle technique problem may underpin the social dynamic context of rugby union, where 
Table 1 The association between coaching methods and match attitudes and behaviours

\begin{tabular}{|c|c|c|c|c|c|c|c|}
\hline & d & $\chi^{2}$ & p Value & Cramer's V & $\tau-\mathbf{b}$ & ASE & z Value \\
\hline \multicolumn{8}{|l|}{ Individual one-one verbal instruction from coach } \\
\hline Doing what is practised & 16 & 32.35 & 0.01 & 0.23 & 0.30 & 0.07 & 4.61 \\
\hline Proper technique & 16 & 29.55 & 0.02 & 0.22 & 0.29 & 0.07 & 4.32 \\
\hline Bring down ball carrier at all cost & 16 & 18.46 & 0.30 & 0.17 & 0.14 & 0.07 & 2.20 \\
\hline Own safety & 16 & 34.75 & 0.00 & 0.24 & 0.20 & 0.07 & 3.01 \\
\hline Safety of ball carrier & 16 & 21.99 & 0.14 & 0.19 & 0.16 & 0.07 & 2.46 \\
\hline Safety of both you and ball carrier & 16 & 10.16 & 0.86 & 0.13 & 0.12 & 0.07 & 1.83 \\
\hline Putting in a 'Big Hit' & 16 & 19.20 & 0.26 & 0.18 & 0.18 & 0.07 & 2.66 \\
\hline Going for the ball only & 16 & 31.06 & 0.01 & 0.22 & 0.25 & 0.06 & 3.98 \\
\hline Staying on your feet & 16 & 31.76 & 0.01 & 0.23 & 0.33 & 0.06 & 5.57 \\
\hline Preventing the ball carrier from retaining possession & 12 & 16.37 & 0.18 & 0.19 & 0.19 & 0.07 & 2.96 \\
\hline Preventing the ball carrier team from retaining possession & 16 & 27.93 & 0.03 & 0.21 & 0.27 & 0.06 & 4.30 \\
\hline \multicolumn{8}{|l|}{ Verbal instruction to entire team } \\
\hline Doing what is practised & 16 & 47.13 & 0.00 & 0.27 & 0.28 & 0.07 & 4.13 \\
\hline Proper technique & 16 & 36.78 & 0.00 & 0.24 & 0.23 & 0.07 & 3.39 \\
\hline Bring down ball carrier at all cost & 16 & 13.44 & 0.64 & 0.15 & 0.10 & 0.07 & 1.50 \\
\hline Own safety & 16 & 32.63 & 0.01 & 0.23 & 0.26 & 0.07 & 3.95 \\
\hline Safety of ball carrier & 16 & 16.18 & 0.44 & 0.16 & 0.17 & 0.07 & 2.67 \\
\hline Safety of both you and ball carrier & 16 & 23.00 & 0.11 & 0.19 & 0.18 & 0.06 & 2.93 \\
\hline Putting in a 'Big Hit' & 16 & 9.58 & 0.89 & 0.12 & 0.07 & 0.06 & 1.06 \\
\hline Going for the ball only & 16 & 25.42 & 0.06 & 0.20 & 0.24 & 0.06 & 3.75 \\
\hline Staying on your feet & 16 & 26.57 & 0.05 & 0.21 & 0.29 & 0.06 & 4.62 \\
\hline Preventing the ball carrier from retaining possession & 12 & 18.42 & 0.10 & 0.20 & 0.16 & 0.06 & 2.59 \\
\hline Preventing the ball carrier team from retaining possession & 16 & 19.04 & 0.27 & 0.17 & 0.23 & 0.06 & 3.82 \\
\hline \multicolumn{8}{|l|}{ Individual one-one demonstration } \\
\hline Doing what is practised & 16 & 62.63 & 0.00 & 0.32 & 0.27 & 0.07 & 4.22 \\
\hline Proper technique & 16 & 41.59 & 0.00 & 0.26 & 0.29 & 0.07 & 4.28 \\
\hline Bring down ball carrier at all cost & 16 & 33.14 & 0.01 & 0.23 & 0.22 & 0.06 & 3.44 \\
\hline Own safety & 16 & 22.93 & 0.12 & 0.19 & 0.22 & 0.07 & 3.26 \\
\hline Safety of ball carrier & 16 & 30.73 & 0.02 & 0.22 & 0.17 & 0.07 & 2.52 \\
\hline Safety of both you and ball carrier & 16 & 29.96 & 0.02 & 0.22 & 0.18 & 0.07 & 2.56 \\
\hline Putting in a 'Big Hit' & 16 & 17.62 & 0.35 & 0.17 & 0.12 & 0.07 & 1.86 \\
\hline Going for the ball only & 16 & 23.01 & 0.11 & 0.19 & 0.22 & 0.06 & 3.55 \\
\hline Staying on your feet & 16 & 29.39 & 0.02 & 0.22 & 0.28 & 0.06 & 4.51 \\
\hline Preventing the ball carrier from retaining possession & 12 & 16.67 & 0.16 & 0.19 & 0.15 & 0.07 & 2.26 \\
\hline Preventing the ball carrier team from retaining possession & 16 & 24.76 & 0.07 & 0.20 & 0.24 & 0.06 & 3.75 \\
\hline \multicolumn{8}{|l|}{ Demonstration to team } \\
\hline Doing what is practised & 16 & 45.14 & 0.00 & 0.27 & 0.26 & 0.07 & 3.76 \\
\hline Proper technique & 16 & 50.42 & 0.00 & 0.29 & 0.30 & 0.07 & 4.54 \\
\hline Bring down ball carrier at all cost & 16 & 28.89 & 0.03 & 0.22 & 0.16 & 0.06 & 2.46 \\
\hline Own safety & 16 & 26.99 & 0.04 & 0.21 & 0.25 & 0.06 & 4.02 \\
\hline Safety of ball carrier & 16 & 27.59 & 0.04 & 0.21 & 0.18 & 0.07 & 2.51 \\
\hline Safety of both you and ball carrier & 16 & 18.69 & 0.29 & 0.17 & 0.19 & 0.07 & 2.94 \\
\hline Putting in a 'Big Hit' & 16 & 13.14 & 0.66 & 0.15 & 0.14 & 0.07 & 2.08 \\
\hline Going for the ball only & 16 & 32.17 & 0.01 & 0.23 & 0.27 & 0.07 & 4.11 \\
\hline Staying on your feet & 16 & 50.17 & 0.00 & 0.29 & 0.38 & 0.06 & 6.23 \\
\hline Preventing the ball carrier from retaining possession & 12 & 16.55 & 0.17 & 0.19 & 0.16 & 0.07 & 2.38 \\
\hline Preventing the ball carrier team from retaining possession & 16 & 21.06 & 0.18 & 0.18 & 0.23 & 0.06 & 3.68 \\
\hline
\end{tabular}

Significant association $p<0.05$. Cramer's $V$ or $\tau$-b less than $0.2=$ weak, between 0.2 and $0.49=$ moderate, and 0.5 and higher=strong relationship.

$|z| \geq 1.96$ is significant at the $p<0.05$ level, $|z| \geq 2.60$ is significant at the $p<0.01$ level and $|z| \geq 3.32$ is significant at the $p<0.001$ level. $d=d e g r e e s$ of freedom. 'Big Hit' - a physically dominating tackle.

players do not want to be singled out for poor technique in fear of being judged by their teammates. ${ }^{38}$ Therefore, when correcting a player's tackle technique, the social context when delivering the technical instruction or demonstration should be considered.
Match tackle type demands are replicated in training

There were moderate associations between the type of tackle coached during training and the type of tackle executed in matches. The most frequently coached tackle during training was the front on tackle, which the 
Table 2 The association between how tackle technique is corrected and match attitudes and behaviours

\begin{tabular}{llllllll}
\hline & $\mathbf{d}$ & $\chi^{\mathbf{2}}$ & $\mathbf{p}$ Value & Cramer's $\mathbf{V}$ & $\boldsymbol{\tau}$-b & ASE & $\mathbf{z}$ Value \\
\hline Identifying a problem in your tackle technique and fixing it & & & & & & \\
$\quad$ Doing what is practised & 16 & 19.63 & 0.24 & 0.18 & 0.21 & 0.07 & 3.07 \\
Proper technique & 16 & 16.14 & 0.44 & 0.16 & 0.17 & 0.07 & 2.33 \\
Bring down BC at all cost & 16 & 22.82 & 0.12 & 0.19 & 0.13 & 0.07 & 1.91 \\
Own safety & 16 & 15.83 & 0.47 & 0.16 & 0.14 & 0.07 & 1.99 \\
Safety of BC & 16 & 20.66 & 0.19 & 0.18 & 0.05 & 0.07 & 0.78 \\
Safety of both you and BC & 16 & 16.81 & 0.40 & 0.16 & 0.02 & 0.07 & 0.36 \\
Putting in a 'Big Hit' & 16 & 12.92 & 0.68 & 0.14 & 0.03 & 0.07 & 0.36 \\
Going for the ball only & 16 & 26.93 & 0.04 & 0.21 & 0.21 & 0.07 & 3.26 \\
Staying on your feet & 16 & 22.44 & 0.13 & 0.19 & 0.25 & 0.06 & 3.99 \\
Preventing the BC from retaining possession & 12 & 17.28 & 0.14 & 0.19 & 0.20 & 0.06 & 3.25 \\
Preventing the BC team from retaining possession & 16 & 18.12 & 0.32 & 0.17 & 0.15 & 0.07 & 2.11 \\
Identifying a team problem in tackle technique and fixing it & & & & & & & \\
Doing what is practised & 16 & 32.55 & 0.01 & 0.23 & 0.29 & 0.06 & 4.56 \\
Proper technique & 16 & 25.41 & 0.06 & 0.20 & 0.25 & 0.06 & 3.88 \\
Bring down BC at all cost & 16 & 16.90 & 0.39 & 0.17 & 0.10 & 0.07 & 1.53 \\
Ownn safety & 16 & 26.37 & 0.05 & 0.21 & 0.23 & 0.06 & 3.70 \\
Safety of BC & 16 & 19.54 & 0.24 & 0.18 & 0.21 & 0.06 & 3.45 \\
Safety of both you and BC & 16 & 16.72 & 0.40 & 0.16 & 0.19 & 0.06 & 3.00 \\
Putting in a 'Big Hit' & 16 & 14.18 & 0.59 & 0.15 & 0.06 & 0.07 & 0.95 \\
Going for the ball only & 16 & 31.17 & 0.01 & 0.22 & 0.19 & 0.07 & 2.96 \\
Staying on your feet & 16 & 26.92 & 0.04 & 0.21 & 0.28 & 0.06 & 4.68 \\
Preventing the BC from retaining possession & 12 & 9.47 & 0.66 & 0.14 & 0.14 & 0.07 & 2.05 \\
Preventing the BC team from retaining possession & 16 & 15.47 & 0.49 & 0.16 & 0.17 & 0.07 & 2.61 \\
\hline
\end{tabular}

Significant association $p<0.05$. Cramer's $V$ or $\tau$-b less than $0.2=$ weak, between 0.2 and $0.49=$ moderate, and 0.5 and higher $=$ strong relationship. $|z| \geq 1.96$ is significant at the $p<0.05$ level, $|z| \geq 2.60$ is significant at the $p<0.01$ level and $|z| \geq 3.32$ is significant at the $p<0.001$ level. $d=$ degrees of freedom. 'Big Hit' - a physically dominating tackle.

$\mathrm{BC}$, ball carrier.

players also reported to be the most often executed tackle in matches. From video analysis studies of tackle events in matches, we know that the front tackle is the most frequently occurring type tackle in a match, and is the tackle type that places players at the highest risk of injury. ${ }^{23} 2539$ The relationship between the type of tackle coached during training and the type of tackle executed in matches is a positive finding as it suggests that for some aspects of tackle training, coaches are replicating match demands.

\section{Strengths, limitations and implications}

A key strength of this study is the large sample size. Nine out of the 10 schools approached participated in the study. This amounted to 164 returned questionnaires (out of a possible 220), representing a $75 \%$ response rate. The questionnaire was able to survey detailed information on tackle training and match play attitudes and behaviours of adolescent rugby players. Despite efforts to word all questions and items as clearly and unambiguously as possible, and provide definitions where necessary, a level of subjectivity and construal is expected because of the inherent limitation of using a self-reported questionnaire. Also, all questionnaires were not completed in examination conditions with the principle investigator present as was planned in the study proposal. During data collection, this was logistically challenging and some questionnaires had to be completed during team meetings or returned at a later stage.

Table 3 The association between training frequency for the different type of tackles and the amount of time the different type of tackles was executed in matches

\begin{tabular}{llllllll}
\hline Type of tackles & $\mathbf{d}$ & $\boldsymbol{\chi}^{\mathbf{2}}$ & $\mathbf{p}$ Value & Cramer's V & $\boldsymbol{\tau}$-b & ASE & $\mathbf{z}$ Value \\
\hline Front-on tackle training vs front-on tackle matches & 20 & 41.27 & 0.00 & 0.25 & 0.28 & 0.06 & 4.54 \\
Side-on tackle training vs side-on tackle matches & 15 & 27.68 & 0.02 & 0.24 & 0.14 & 0.07 & 1.98 \\
Smother tackle training vs smother tackle matches & 20 & 35.88 & 0.02 & 0.24 & 0.21 & 0.07 & 3.09 \\
Behind tackle training vs behind tackle matches & 20 & 30.46 & 0.06 & 0.22 & 0.13 & 0.07 & 1.79 \\
Double tackle training vs double tackle matches & 20 & 49.28 & 0.00 & 0.28 & 0.24 & 0.07 & 3.36 \\
\hline
\end{tabular}

Significant association $p<0.05$. Cramer's $V$ or $\tau$-b less than $0.2=$ weak, between 0.2 and $0.49=$ moderate, and 0.5 and higher $=$ strong relationship. $|z| \geq 1.96$ is significant at the $p<0.05$ level, $|z| \geq 2.60$ is significant at the $p<0.01$ level and $|z| \geq 3.32$ is significant at the $p<0.001$ level. $d=$ degrees of freedom. 


\section{Summary}

This is the first study to report on the relationships between players' training attitudes and behaviour and their match attitudes and behaviours for tackling in rugby union. The importance of tackle training to prevent injury, and the amount of time spent on technique to prevent injuries, was associated with behaviours that reduce the risk of injury in matches. Match behaviours 'doing what is practised', 'proper technique', 'own safety' and 'staying on feet' were consistently associated with both verbal instruction and demonstration, which suggest that these coaching methods may be effective for training contact skills such as tackling.

Twitter Follow Sharief Hendricks at @Sharief_H and Mike Lambert at @MikeLambert 01

Contributors $\mathrm{SH}$ is responsible for conceptualisation, data analysis and write-up. SdH assisted with analysis. NT assisted with data collection. JB assisted with write-up. ML assisted with conceptualisation and write-up.

Competing interests None declared.

Ethics approval UCT Health Science Human Research Ethics Committee.

Provenance and peer review Not commissioned; internally peer reviewed.

Open Access This is an Open Access article distributed in accordance with the Creative Commons Attribution Non Commercial (CC BY-NC 4.0) license, which permits others to distribute, remix, adapt, build upon this work noncommercially, and license their derivative works on different terms, provided the original work is properly cited and the use is non-commercial. See: http:// creativecommons.org/licenses/by-nc/4.0/

\section{REFERENCES}

1. Kok G, Bouter LM. On the importance of planned health education. Prevention of ski injury as an example. Am J Sports Med 1990;18:600-5.

2. van Mechelen W, Hlobil H, Kemper HC. Incidence, severity, aetiology and prevention of sports injuries. A review of concepts. Sports Med 1992;14:82-99.

3. Verhagen EA, van Stralen MM, Van Mechelen W. Behaviour, the key factor for sports injury prevention. Sports Med 2010;40:899-906.

4. Eime R, Owen N, Finch C. Protective eyewear promotion: applying principles of behaviour change in the design of a squash injury prevention programme. Sports Med 2004;34:629-38.

5. Lund J, Aarø LE. Accident prevention. Presentation of a model placing emphasis on human, structural and cultural factors. Saf Sci 2004; 42:271-324.

6. Van Tiggelen D, Wickes S, Stevens V, et al. Effective prevention of sports injuries: a model integrating efficacy, efficiency, compliance and risk-taking behaviour. Br J Sports Med 2008;42:648-52.

7. Collard D, Singh A, Verhagen E. The behavioural approach. In: Verhagen E, van Mechelen W, eds. Sports injury research. New York: Oxford University Press, 2010:157-66.

8. Emery CA, McKay CD, Campbell TS, et al. Examining attitudes toward body checking, levels of emotional empathy, and levels of aggression in body checking and non-body checking youth hockey leagues. Clin J Sport Med 2009;19:207-15.

9. Finch CF, Mclntosh AS, McCrory P. What do under 15 year old schoolboy rugby union players think about protective headgear? Br J Sports Med 2001;35:89-94.

10. Finch C, Donohue S, Garnham A. Safety attitudes and beliefs of junior Australian football players. Inj Prev 2002;8:151-4.

11. Gianotti SM, Quarrie KL, Hume PA. Evaluation of RugbySmart: a rugby union community injury prevention programme. J Sci Med Sport 2009;12:371-5

12. Osberg JS, Stiles SC. Safety behavior of in-line skaters. Inj Prev 2000;6:229-31.

13. Pettersen JA. Does rugby headgear prevent concussion? Attitudes of Canadian players and coaches. Br J Sports Med 2002;36:19-22.
14. Donaldson A, Finch C. Planning for implementation and translation: seek first to understand the end-users' perspectives. $\mathrm{Br} J$ Sports Med 2012;46:306-7.

15. Finch C. A new framework for research leading to sports injury prevention. J Sci Med Sport 2006;9:3-9.

16. Hendricks S, Jordaan E, Lambert MI. Attitude and behaviour of junior rugby union players towards tackling during training and match play. Saf Sci 2012;50:266-84.

17. Verhagen E, Voogt N, Bruinsma A, et al. A knowledge transfer scheme to bridge the gap between science and practice: an integration of existing research frameworks into a tool for practice. Br J Sports Med 2014;48:698-701.

18. Côté J, Baker J, Abernethy B. Practice and play in the development of sport expertise. In: Tenenbaum G, Eklund R, eds. Handbook of sport psychology. 3rd edn. New Jersey: John Wiley and Sons, 2007:184-202.

19. Williams AM, Hodges NJ. Practice, instruction and skill acquisition in soccer: challenging tradition. J Sports Sci 2005;23:637-50.

20. Smart D, Hopkins WG, Quarrie KL, et al. The relationship between physical fitness and game behaviours in rugby union players. Eur $J$ Sports Sci 2014;14(Suppl 1):S8-S17.

21. Brooks JH, Fuller CW, Kemp SP, et al. An assessment of training volume in professional rugby union and its impact on the incidence, severity, and nature of match and training injuries. J Sports $\mathrm{Sci}$ 2008;26:863-73.

22. Hartwig TB, Naughton G, Searl J. Motion analyses of adolescent rugby union players: a comparison of training and game demands. $J$ Strength Cond Res 2011;25:966-72.

23. Hendricks $S$, Lambert $M$. Tackling in rugby: coaching strategies for effective technique and injury prevention. Int J Sports Sci Coach 2010;5:117-35

24. Deutsch MU, Kearney GA, Rehrer NJ. Time-motion analysis of professional rugby union players during match-play. J Sports $\mathrm{Sci}$ 2007;25:461-72.

25. Quarrie KL, Hopkins WG. Tackle injuries in professional rugby union. Am J Sports Med 2008;36:1705-16.

26. Hendricks S, Lambert MI. Theoretical model describing the relationship between the number of tackles in which a player engages, tackle injury risk and tackle performance. J Sports Sci Med 2014:13:715-17.

27. Schwellnus MP, Thomson A, Derman W, et al. More than $50 \%$ of players sustained a time-loss injury ( $>1$ day of lost training or playing time) during the 2012 Super Rugby Union Tournament: a prospective cohort study of 17,340 player-hours. Br J Sports Med 2014:48:1306-15.

28. Freitag A, Kirkwood G, Scharer S, et al. Systematic review of rugby injuries in children and adolescents under 21years. Br J Sports Med 2015;49:511-19.

29. Hendricks S, Matthews B, Roode B, et al. Tackler characteristics associated with tackle performance in rugby union. Eur J Sports Sci 2014;14:753-62.

30. Chalmers DJ, Simpson JC, Depree R. Tackling rugby injury: lessons learned from the implementation of a five-year sports injury prevention program. J Sci Med Sport 2004;7:74-84.

31. Gabbett $T$, Ryan $P$. Tackling technique, injury prevention, and playing performance in high-performance collision sport athletes. Int J Sports Sci Coach 2009;4:521-33.

32. Babbie E. The practice of social sciences. Belmont: Thomson Wadsworth, 2004.

33. Czaja R, Blair J. Designing surveys. A guide to decisions and procedures. London: Pine Forge Press, 2005.

34. Dillman DA. Mail and internet surveys. The tailored design method. New Jersey: John Wiley and Sons Inc, 2007.

35. Viljoen W, Patricios J. BokSmart-implementing a National Rugby Safety Programme. Br J Sports Med 2012;46:692-3.

36. Brown JC, Verhagen E, Knol D, et al. The effectiveness of the nationwide BokSmart rugby injury prevention program on catastrophic injury rates. Scand J Med Sci Sports 2015. doi:10.1111/ sms. 12414

37. Brown JC, Lambert MI, Hendricks S, et al. Are we currently underestimating the risk of scrum-related neck injuries in rugby union front-row players? Br J Sports Med 2014;48:1127-9.

38. Fraser-Thomas J, Côté J. Understanding adolescents' positive and negative developmental experiences in sport. Sport Psychol 2009;23:3-23.

39. Burger N, Lambert MI, Viljoen W, et al. Tackle-related injury rates and nature of injuries in South African Youth Week tournament rugby union players (under-13 to under-18): an observational cohort study. BMJ Open 2014;4:e005556. doi:10.1136/ bmjopen-2014-005556 
The relationships between rugby players' tackle training attitudes and behaviour and their match tackle attitudes and behaviour

Sharief Hendricks, Steve den Hollander, Nicholas Tam, James Brown and Michael Lambert

BMJ Open Sport Exerc Med 2015 1:

doi: 10.1136/bmjsem-2015-000046

Updated information and services can be found at:

http://bmjopensem.bmj.com/content/1/1/e000046

Email alerting service

These include:

References This article cites 33 articles, 14 of which you can access for free at: http://bmjopensem.bmj.com/content/1/1/e000046\#BIBL

Open Access This is an Open Access article distributed in accordance with the Creative Commons Attribution Non Commercial (CC BY-NC 4.0) license, which permits others to distribute, remix, adapt, build upon this work non-commercially, and license their derivative works on different terms, provided the original work is properly cited and the use is non-commercial. See: http://creativecommons.org/licenses/by-nc/4.0/

Receive free email alerts when new articles cite this article. Sign up in the box at the top right corner of the online article.

\section{Notes}

To request permissions go to:

http://group.bmj.com/group/rights-licensing/permissions

To order reprints go to:

http://journals.bmj.com/cgi/reprintform

To subscribe to BMJ go to:

http://group.bmj.com/subscribe/ 